Peshawar Journal of Psychology and Behavioral Sciences, 2015, Vol. 1, No. 1, 15-31

\title{
Effects of Attachment Styles on Adolescents
}

\author{
Ishrat Rehman ${ }^{1}$ and Madiha Asghar ${ }^{2}$ \\ Islamia College Peshawar
}

The purpose of this study was to examine adolescent's attachment with parents and its association with anger, life satisfaction and sociability. The sample of the study was selected from different high schools and colleges in Peshawar through convenience sampling method. Sample of four hundred $(\mathrm{N}=400)$ students with age range of 14 to 18 years and mean age calculated for total sample as 15.54 years, the sample further comprised of two hundred $(\mathrm{n}=200)$ boys with mean age of 15.05 and two hundred $(\mathrm{n}=200)$ girls with mean age of 16.02 years. Tools used in the study included perceived child parent attachment scale for mother, perceived child parent attachment scale for father, the clinical anger scale, sociability scale and satisfaction with life scale all were self-administered. Results revealed significant negative correlation between insecure attachment style and sociability. Results shown that adolescents who scored higher on avoidant and ambivalent attachment styles were positively associated with anger and negatively linked with secure attachment. While perceived child parent attachment had not a significant impact on life satisfaction of adolescents. The findings of present study revealed that insecure attachment styles were positively linked with anger and negatively linked with sociability among adolescents. Boys showed more anger score as compared to girls and there was not significant difference on sociability and life satisfaction scores among girls and boys. It is concluded that perceived child parents attachment styles plays a key part in the development of anger, sociability and life satisfaction among adolescents.

Keywords. Attachment styles, parenting, adolescents, anger, life satisfaction and sociability

We form different relationship with others throughout our life, but the most important relationship is considered the relationship between parent and child (Steinberg, 2001). The relationship begins to

${ }^{1}$ MS Scholar, Department of Psychology, Islamia College Peshawar

${ }^{2}$ Assistant Professor, Department of Psychology, Islamia College Peshawar 
change unusually in early adolescence, but individuation theory emphasizes that close and supportive relationship with parents are still considered to be important, (Collin \& Steinberg 2006). Adolescence is the period that has been considered as unique, being anxious with disruption of emotion and fights with those in power, so it's important to concentrate on this age (Hall 1994). Researcher also said that Adolescence is the age of "snowstorm" in which quick fluctuations in emotional and physical growth unavoidably lead to clashes among adolescents and attachment figures (Hall, 1994).

Psychologist Mary Ainsworth defined attachment as "affection ties between human being and animals which they form between themselves or in other words a connection which binds them together in space and endure over time." Attachment involves a desire for regular contact between two people, while they experienced distress during separation. The child's attachment from early years is towards their parent figures that take care and provides emotional and physical security. These attachment bonds shifts towards friend in early adolescence, and then towards partner and eventually towards their own child's in adulthood. Positive attachment bonding with caregiver, support the kid and adolescents to attain their complete intellectual potential, they perceive and interpret the surrounding in a reasonable good manners, they develops societal sentiments and integrity and begin belief on others as outcome of healthy relation with caregiver. They make friends easily, cope stress in a managing way, develop self-worth, jealousy and envy, and overcome fear and worries. Those child's who are well attached with one caregiver, can make more easily relation with others e.g. siblings and other family members. Attachment is formed in early childhood or in adolescence has great effect on later life (Ainsworth 1970).

Different research studies showed that anger is positively correlated with insecure and negatively linked with secure attachment styles, on the other hand life satisfaction and sociability are negatively associated with avoidant and ambivalent attachment styles, and as well life satisfaction 
and sociability is positively correlated with secure attachment style of adolescents.

Results indicated that those adolescents who categorized themselves insecurely (avoidant and ambivalent) attached with their parents showed more anger and hostility as compared to securely attached adolescents. (Meesters, Morren, Moorman \& Muris, 2004).

A study by Bloodworth (N-I) revealed that if a person had a positive relation with their caretaker as a kid (secure attachment style), then he/she would have a negligible amount of hostile behaviors as an adult.

Parent's attachment with their children also plays a great role in adolescent's sociability, so further studies provided to highlight the association between attachment and sociability. A study by Haft \& Slade (1989) which were found that securely attached adults have a tendency to be more skillful, more comfortable in handling different types of relationships, and more sociable. A study was designed for the purpose to find out relationship among attachment styles and social skills, results indicated that those individuals who were securely attached showed higher social skills as compared to insecure individuals, (Hori \& Kobayashi, 2010). A study conducted for the purpose to explore the relationship among attachment styles and social skills among Japanese pupils. Outcomes indicated that the fearful and dismissing attachment styles were associated to lower scores on many social skills (Junichi \& Koju, 2013).

Afterwards some studies stressed the importance of life satisfaction and child parent's attachment. Ozdemir \& Koruko (2013) specified that both attachment with father and mother is strongly related with life satisfaction, while in school attachment scale, only attachment to teacher related with life satisfaction of adolescents. Another study observed that weak parental bond, and not intimate relationship, was linked with low life satisfaction between a group of Canadian adolescents (Grossman \&Rowat, 1995). Another research study point out that Chines early adolescent's life satisfaction was related with parental warmth. (McBride, Leung, Wong, \& Wong, 2010). 


\section{Hypotheses}

1. Adolescents with secured parental attachment will have less anger than those with insecure attachment with parents.

2. Insecure ambivalent and insecure avoidant attachment styles will decrease life Satisfaction and sociability scores among adolescents.

\section{Sample}

\section{Method}

The survey model was used in the present study. The sample of the research was selected from several government and private high schools and colleges in Peshawar by convenience sample technique. Total 400 students filled up self-administered questionnaires which were comprised of 200 male and 200 female adolescents. Participant's age ranged from 14-18 (class $8^{\text {th }}$ to $12^{\text {th }}$ ) with a mean age of 15.54.Intact families adolescents participated in the research study and orphans were excluded.

\section{Instruments}

Participants of the study filled up all required self-administered questionnaires, which were delivered by the researcher of the study.

\section{Demographic Information}

Demographic information contains general information of study participants. Information concerning name, age, sex, birth order, mother alive, father alive, monthly income, grade, residence and education of parents. 


\section{Perceived Child-Parent Attachment Scale}

The perceived-child parent attachment scale is self-report measure scale that measure adolescent's opinions of their affection towards their parents. This self-constructed questionnaire is in Urdu language, the perceived child parent attachment scale is composed of 30 items, further it has two parts one for mother attachment and second for father attachment each one has 15 items. Further this scale is divided into three subscales, which identified the three attachment styles: secure, insecure avoidant and insecure ambivalent, each one is composed of 10 items. The children asked to read each item carefully and to rate the degree to which the item defined themselves on a 4 point scale with score extending from 4 (always) to 1(very rare). High score on one subscale categorized adolescents in secure, avoidant or ambivalent attachment style.

Alpha reliability of perceived child parent attachment scale as a whole is .780 , and alpha reliability for each sub scale is .751 for secure attachment, .619 for avoidant attachment and .687 for ambivalent attachment.

\section{Clinical Anger Scale}

William Snell developed anger scale, this is an objective selfreport measure, which is intended to measure the psychological indicators supposed to have importance in considerate and conduct of anger. Total twenty one group of statement with options from A to D are

given in the scale, which is constructed on the set-up from one of the early of Beck's initial tools was used to intention the Clinical Anger Scale. Participants were asked to read each statement of the 21 groups and to choose the single statements that best describe how they sensed. Subjects' responses were CAS were summed up, CAS scoring is accomplish by the following informative series: 0-13 minimal anger, 1419 mild anger, 20-28 moderate anger and 29-63 indicates severe anger. Alpha reliability of the scale is .780 .

\section{Life Satisfaction Scale}

Peshawar Journal of Psychology and Behavioral Sciences, 2015, Vol. 1, No. 1, 15-31 
Diener developed satisfaction with life scale for the purpose to discourse the concept of life satisfaction as a full relatively than to evaluate satisfaction through sub-dimension of life. SWLS measures the "inconsistency or stability" between one's life achievement and expectations (Diener et.all, 1985) stated an internal consistency of .87 and a test re test co efficient .82 done within two month of period with lessening to .54 above a long period.

Questionnaire is consists of five items with a seven point Likert scale ranging from strongly disagree to (1) to (strongly) powerfully agree (7). A total score (5-35) is calculated by summing the score of individually answer. The scale is available in multiple languages; no specific training is required to administer this scale. The SWLS can be completed in less than five minutes. The translated version of SWLS in Urdu language remained used in the current study. Low score on scale indicated low level of life satisfaction whereas high scores indicated high level of life satisfaction. 15-19 shows somewhat below average score, average score is 20-24, high score is $25-29$ and $30-35$ indicated very satisfied. Alpha reliability of the scale is .580 .

\section{The Sociability Questionnaire}

The sociability questionnaire was constructed by Jonathan Beret, A.C.S.W \& Associates, for the purpose to determine the amount of an individual's common contest. The scale is applied on adolescents and grownups and parents of such dependent parents. Scale comprises of 35 items with true and false option, high score on sociability questionnaire indicates high sociability skills. The basic aim of construction of this scale to provide five types of data that is associated to socialization. Categories include: Empathy, knowledge of social etiquette (the rules indicating the proper and polite way to behave), concept and self, social anxiety, feelings towards parents, and degree of independence.

Scale is composed of 35 items with "true" and "false" options. When rating the question each correct answer a worth of 1 . All the 
correct answers define the total score of an individual. There is no "right" or "wrong" answers in a complete sense; though, a right response replicates a well ability with social skills. Guidelines for interpreting test score 17 or below indicates low score, 18-27 indicates medium score while above than 28 indicates high score on the scale. Alpha reliability of the scale is .499 .

\section{Procedure}

After seeking formal permission from the schools and colleges administrations. The scholar talked the students together and providing a summary of the nature of the scales items, directions in what way to complete the questionnaire and behavior procedures, such as not speaking to others, and asking for help. When rapport established with the students they were instructed for their true and honest opinions in answering the questions. The researcher and one or two assistants were accessible to reply to student's requests and worries during the data gathering. The period essential for concluding the scales varied about one hour.

Information was collected in class rooms setting in a group form of children from different high schools and colleges in Peshawar. Difficulty in understanding any item in the questionnaires, researcher was available to the participants and all the difficult words and sentences were explained and translated to the participants. Last item of the Clinical Anger Scale was "I don't feel so angry that it interferes with my interest in sex". With the approval of author changed the item to "I don't feel so angry that it interferes with my interest in myself".

\section{Results}

Table 1

Inter Scale Correlation of Predicting and Outcome Variables among Adolescents $(\mathrm{N}=400)$

\begin{tabular}{llllllll}
\hline & Scales & 1 & 2 & 3 & 4 & 5 & 6 \\
\hline 1 & SA & - & & & & &
\end{tabular}




\begin{tabular}{|c|c|c|c|c|c|c|}
\hline 2 & $\mathrm{AA}$ & $.116^{*}$ & - & & & \\
\hline 3 & AtV & $.48 * *$ & $.24 * *$ & - & & \\
\hline 4 & SS & $-.11 *$ & $-.21 * *$ & $-.38 * *$ & - & \\
\hline 5 & CAS & -.05 & $.20 * *$ & $.14 * *$ & $-.19 * *$ & - \\
\hline 6 & SS & .006 & -.006 & .06 & -.04 & -.05 \\
\hline
\end{tabular}

Table 2

Multiple Regression Analysis of Perceived Child Parent Attachment Predicting Anger among Secure and Insecure Adolescents $(\mathrm{N}=400)$

\begin{tabular}{lcccccc}
\hline & & $\begin{array}{c}\text { Secure } \\
(\mathrm{n}=314)\end{array}$ & & & $\begin{array}{c}\text { Insecure } \\
(\mathrm{n}=86)\end{array}$ & \\
\hline Variables & $\mathrm{B}$ & $\mathrm{SE}$ & $\mathrm{B}$ & $\mathrm{B}$ & $\mathrm{SE}$ & $\mathrm{B}$ \\
\hline Constant & 14.655 & 4.790 & & 29.75 & 5.740 & \\
& & & & 7 & & \\
Secure & -.362 & $.155^{*}$ & -.152 & -.717 & .353 & -.484 \\
$\mathrm{AtA}$ & .355 & $.123^{* * *}$ & .161 & .501 & $.155^{* * *}$ & .345 \\
$\mathrm{AA}$ & .583 & $.127 * * *$ & .297 & .222 & .348 & .149 \\
$\mathrm{R}^{2}$ & .096 & & & .179 & & \\
$\mathrm{~F}$ & 10.954 & & & 5.954 & & \\
& $* * *$ & & & $* * *$ & & \\
\hline Note. ${ }^{*} p<.05, \quad{ }^{* *} p<.01$ & $\& * * * p<.001$. & AtA $=$ & Avoidant & Attachment, & AA $=$ \\
Ambivalent Attachment & & & & &
\end{tabular}

Table 2 shows perceived child parent attachment style as a predictor of anger among secure and insecure adolescents. The analysis shows significant regression equation between perceived child parent attachment styles and anger responded by secure adolescents $F(3,310)$, 10.954; the table is statistically significant at $p<.001$ with variance $R^{2}$ of .096 and adjusted $\mathrm{R}^{2}$ is .087 . Perceived child parent attachment styles 
also explain significant amount of variance responded by insecure adolescents $\mathrm{F}(3,82) ; 5.954, \mathrm{p}<.001, \mathrm{R}^{2}$ of .179 and adjusted $\mathrm{R}^{2}$ is .149 . Results reveals that perceived child parent attachment style predicts anger among secure and insecure adolescents.

Table 3

Mean Difference and t-Value of Secure and Insecure Adolescents on Sociability Scale $(\mathrm{N}=400)$

\begin{tabular}{lcccccccc}
\hline \multirow{2}{*}{ Groups } & $\mathrm{M}$ & $\mathrm{SD}$ & $\mathrm{t}(2)$ & $\mathrm{Sig}$ & \multicolumn{2}{c}{$95 \% \mathrm{CI}$} & \multirow{2}{*}{ Cohen's d } \\
\cline { 6 - 7 } Secure & 21.24 & 3.73 & 4.190 & .001 & -2.71 & -.98 & 0.53 \\
Insecure & 19.40 & 3.17 & & & & & \\
\hline Note. ${ }^{*} p<.05,{ }^{* * p} p .01$ & $* * * p<.001$ & & & &
\end{tabular}

Table 3 displays t-value and mean difference of secure and insecure adolescents on sociability scale. This shows that secure adolescents shows greater score as related to insecure, mean difference is 1.84. Result shows significant difference in sociability score among secure and insecure adolescents, and Cohen's $d$ value 0.531 shows that here is large influence and variance between secure and insecure adolescents.

Table 4

Multiple Regression Analysis of Perceived Child Parent Attachment Style Predicting Sociability among Secure and Insecure Adolescents $(\mathrm{N}=400)$

\begin{tabular}{lllllll}
\hline & & $\begin{array}{c}\text { Secure } \\
(\mathrm{n}=314)\end{array}$ & & \multicolumn{3}{c}{$\begin{array}{c}\text { Insecure } \\
(\mathrm{n}=86)\end{array}$} \\
\hline Variables & $\mathrm{B}$ & $\mathrm{SE}$ & $\mathrm{B}$ & $\mathrm{B}$ & $\mathrm{SE}$ & $\beta$ \\
\hline Constant & 30.262 & 1.758 & & 22.430 & 2.221 & \\
Secure & .059 & .057 & .064 & -.132 & .137 & -.245 \\
AtA & -.142 & $.045^{* * *}$ & -.168 & .050 & .060 & .095 \\
AA & -.295 & $.046^{* * *}$ & -.390 & -.007 & .135 & -.013 \\
$\mathrm{R}^{2}$ & .178 & & & .064 & & \\
\hline
\end{tabular}

Peshawar Journal of Psychology and Behavioral Sciences, 2015, Vol. 1, No. 1, 15-31 


\begin{tabular}{ccc}
\hline $\mathrm{F}$ & $22.34 * * *$ & 1.862 \\
Note. & $* p<.05, \quad * * p<.01$ & $\& * * * p<.001$.
\end{tabular}
Ambivalent Attachment

Table 4 shows perceived child parent attachment style as a predictor of sociability among secure and insecure adolescents. The analysis shows significant regression equation between perceived child parent attachment styles and sociability among secure adolescents $\mathrm{F}$ $(3,310), 22.344$; the table is statistically significant at $\mathrm{p}<.001$ with variance $\mathrm{R}^{2}$ of .178 and adjusted $\mathrm{R}^{2}$ is .170 . Perceived child parent attachment style also explain significant amount of variance in sociability respondents by insecure adolescents $\mathrm{F}(3,82) ; 1.862, \mathrm{p}<.142$, $\mathrm{R}^{2}$ of .064 and adjusted $\mathrm{R}^{2}$ is .030 . Results reveals that perceived child parent attachment style predicts sociability among secure and insecure adolescents.

Table 5

Multiple Regression Analysis of Perceived Child Parent Attachment Predicting life Satisfaction among Secure and Insecure Adolescents $(\mathrm{N}=400)$

\begin{tabular}{lllllll}
\hline & & $\begin{array}{c}\text { Secure } \\
(\mathrm{n}=314)\end{array}$ & & $\begin{array}{l}\text { Insecure } \\
(\mathrm{n}=86)\end{array}$ \\
\hline Variables & $\mathrm{B}$ & $\mathrm{SE}$ & $\mathrm{B}$ & $\mathrm{B}$ & $\mathrm{SE}$ & $\beta$ \\
\hline Constant & 25.03 & $2.519 * *$ & & 25.07 & $4.544^{* *}$ & \\
& 3 & $*$ & & 2 & $*$ & \\
Secure & .004 & .081 & .004 & .072 & .279 & .067 \\
Avoidant & -.039 & .065 & -.036 & -.057 & .122 & -.054 \\
Ambivale & .038 & .067 & .039 & .015 & .276 & .014 \\
$\mathrm{nt}$ & & & & & & \\
$\mathrm{R}^{2}$ & .002 & & & .008 & & \\
$\mathrm{~F}$ & .241 & & & .207 & & \\
\hline
\end{tabular}


Note. ${ }^{*} p<.05, * * p<.01 \& * * * p<.001$

Table 5 shows perceived child parent attachment style as a predictor of life satisfaction among secure and insecure adolescents. Analysis shows that there is no significant regression equation between perceived child parent attachment style and life satisfaction among secure adolescents $\mathrm{F}(3,310), .241$; the table is statistically not significant at $\mathrm{p}<.867$ with variance $\mathrm{R}^{2}$ of .002 and adjusted $\mathrm{R}^{2}$ is -.007 . Perceived child parent attachment style also does not explain significant amount of variance in life satisfaction respondents by insecure adolescents $\mathrm{F}$ (3, $82) ; .207, \mathrm{p}<.891, \mathrm{R}^{2}$ is .008 and adjusted $\mathrm{R}^{2}$ is -.029 . Results reveals that perceived child parent attachment style does not predict life satisfaction among secure and insecure adolescents.

\section{Discussion}

As it is said that adolescents are a clay mud, they can be developed and shaped in different ways. This research study was planned to search the association among perceived child parent attachment style, anger, sociability and life satisfaction among adolescents. It was hypothesized that secure adolescents will show less anger as compare to insecure adolescents. The findings of the present were consistent with the findings of Hymel, \& Konishi, (2014) that revealed dysfunctional anger associated with an insecure attachment style. Greater level of selfreported anger intensity was positively correlated to adolescents who were anxiously and avoidant attached with their father and mother (Chaiki, Hymel, Konishi \& Shelley, 2014), whereas a study conducted by Kaileen $\&$ Pearson, which showed that securely attached adolescents to their parents were less prone to anger. Adolescents who defined themselves as avoidant and ambivalently attached to their parents on self-reported attachment scale showed greater levels of hostility and anger than adolescents who categorized themselves as securely attached to their parents, Meesters, Morren, Moorman \& Muris (2004). A study conducted by (Bean et al, 2004) showed that when parent-child closeness is low then parent-child have a tendency to experience anger and hostility.

Peshawar Journal of Psychology and Behavioral Sciences, 2015, Vol. 1, No. 1, 15-31 
Another hypothesis predicted from previous studies that insecure ambivalent and insecure avoidant attachment styles bring impairment in sociability and life satisfaction among adolescents. Result of the present study revealed consistent findings with previous studies on the same issue i.e., individuals with anxious and fearful attachment styles might display uncertain social relationships, (Bates \& Murphy, 1997) also individuals having dismissing style have a tendency to escape societal relationships (Main et al, 1985), these individuals exhibit similar potential to display insecure social interactions, encouraging lower social skills, comparing with secure individuals. Another study was designed to expose an association among parenting styles and children's sociability, teenagers of authoritative parents were categorized as socially skilled while those of authoritarian parents were regarded socially unskilled. Understood in this conclusion is that, the way and style teenagers are brought up have emotional impact on their social growth, (Alfred, Konnie, Monica \& Mensah, 2013). Another study examined the association among grown up attachment style, with respect to the fourcategory classic and shared abilities among Japanese pupils. Outcomes indicated that the fearful and dismissing styles were associated to lower scores on many social skills (Junichi \& Koju, 2013).

Adolescents insecurely attached with their parents will show low life satisfaction. Overall results show positive relation with secure attachment and negative association with insecure attachment but not significant. The findings of the current study were not in line with other research studies. It might be possible that Army Public School incident might have affected adolescent's scores on life satisfaction scale because research data was collected after that traumatic event in Peshawar.

Hence this research study succeeded in providing evidence that parents have crucial roles in adolescent's sociability, anger and life satisfaction. Therefore, for further research and development in the field of adolescent focus should be on improving adolescent-parent relationship. It would be a contribution in the field of adolescent development in areas such as anger, sociability and life satisfaction. 


\section{Conclusion and Limitation}

Results of this study identified that perceived secure attachment have a good impact on adolescent's wellbeing, they are less prone to anger, they have higher sociability and high life satisfaction, and the other hand avoidant and ambivalent attachment have a worse impact on adolescents. Perceived Avoidant and ambivalent attachment play a major role in the development of anger among adolescents, low sociability and low life satisfaction scores.

Linear regression and multiple regression methods indicated that those adolescents who identified themselves as secure did less score on anger scale as compared to insecure adolescents. Further linear regression, multiple regression and t-test analysis indicated that secure adolescents did higher score on sociability scale as compared to insecure adolescents. Linear and multiple regression were also carried out for finding association among perceived child parent attachment and life satisfaction, which showed positive relationship with secure and ambivalent attachment and negative with avoidant attachment but not significant.

Same analysis was also undertaken to differentiate responses of boys and girls on major study variables. Boys showed more anger as compared to girls, and there was no significant difference for sociability and life satisfaction scores among boys and girls. Overall it is concluded that perceived secure attachment is linked to higher sociability score and less anger score, while perceived insecure attachment is associated with low sociability score and high anger score.

Regardless of few limitations, this research study delivers overall support for the role of perceived child parental attachment on sociability, anger and life satisfaction among adolescents. Research findings are limited for several reasons. First, a larger sample would have made them more convincing. All questionnaires were self-administered that was representing adolescent's opinions about their parents, which may be biased. Our results are not intended to provide information about parents' actual behavior; there may be an important gap between representations of parents by their children and the way they actually behave. It is further suggested for researchers to conduct data from adolescent's parents as well for satisfying this gap.

Peshawar Journal of Psychology and Behavioral Sciences, 2015, Vol. 1, No. 1, 15-31 
Data was collected in class rooms setting in group forms it might be possible that adolescents might take help from their friends, so further it will be beneficial for researchers to collect data individually to avoid such type of replication. Further researches needed to conduct studies on variables such as academic achievement, adolescent's home environment, school environment, attitude of teachers towards students, peer relationship and examination stress etc., which might be affected current study findings. Data collection of this research study was acquired after Army Public school Trauma, suicide bomb blasting happening very often in those days in Peshawar, which might be related to low life satisfaction score in adolescents, because parents were worried about their children safety and security.

It is low-priced way for the management of the schools and colleges to educate the teachers and parents of the children to assess and dealing with psychosocial and relationship difficulties. They can address these issues on teacher-parents meeting or they can arrange a workshop or seminar for guardians and parents to educate them in identifying these issues and compel them for counseling.

\section{References}

Ainsworth, M. D (1970). Attachment, exploration, and Separation: Illustrated by the behavior of one-year-olds in a strange situation. Child Development, 41, 49-67

Bean, S., Lezin, N., Rolleri, L. A., and Taylor, J. (2004). Parent-child connectedness: Implication for research, interventions, and positive impacts on adolescent health.

Bloodworth, E, J, (N-I) Attachment Style and Its Influence on Aggression.

Collins, W. A., and Steinberg, L. (2006). Adolescent development in interpersonal context.

Peshawar Journal of Psychology and Behavioral Sciences, 2015, Vol. 1, No. 1, 15-31 
Grossman, M., and Rowat, K. M. (1995). Parental relationships, coping strategies,

Received support and wellbeing in adolescents of separated or divorced and married parents. Research in Nursing \& Health, 18,249261.

Halft, W. L. and Slade, P. (1987). Romantic love conceptualized as an attachment

Process. Journal of Personality and Social Psychology, 52, 511-524. In Parental

Bonding and Parent-Child Relationship among Tertiary Students.

Hall, G. S. (1994). Adolescence, Its psychology and its relations to physiology,

Anthropology, sociology, sex, crime, religion, and education (Vol. 2). New York: Appleton. Retrieved from: scholarcommons.usf.edu on24-5-2014

Hori, M. and Kobayashi, T. (2010). Association among adult attachment, social skills,

and psychological adjustment for university students. Journal of School Mental Health, 13, 41-48. In Tamaki, K. Takahashi, J (2013) The Relationship between Adult Attachment Style and Social Skills in Terms of the Four-Category Model of Attachment Style. International Journal of Humanities and Social Science Vol 3 No 19 November 2013. Retrived. from www.ijhssnet.com/journal/index/ 2123. On 24-5-2014.

Konishi, C., and Hymel, S. (2014). An attachment perspective on anger among adolescents. Merrill-Palmer Quarterly, 60(1), 5379.InBloodworth, E,J Attachment Style and Its Influence on Aggression.

Leung, A. N. M., Wong, S. S. F., Wong, I. W. Y., and McBride-Chang, C. (2010).

Filial piety and psychosocial adjustment in Hong Kong Chinese early adolescents. Journal of Early Adolescence, 30, 651-667. In Schwarz, B, Mayer, B, Trommsdorff, G, Ben-Arieh,A, Friedlmeier,M, Lubiewska,K,.et all (2012)

Main, M., Kaplan, N., and Cassidy, J. (1985). Security in infancy, childhood, and 
Adulthood: A move to the level of representation. Monograph of the Society for Research in Child Development, 50, 66-104.

Mensah, Monica Konnie, and Kuranchie, Alfred (2013) Influence of Parenting Styles on the Social Development of Children. Academic Journal of Interdisciplinary Studies Vol 2 No 3.

Muris P, Meesters C, Morren M, and Moorman L, (2004) Anger and hostility in adolescent's relationships with self-reported attachment style and perceived parental rearing styles.

Özdemir,Y, and Koruklu,N,. (2013) Parental Attachment, School Attachment and Life Satisfaction in Early Adolescence.

Steinberg, L. (2001). We know some things. Parent-adolescent relationship in retrospective and prospect. Journal of Research on Adolescence, 11(1), 1-19. In Han S, Y, (N-I) In Parental Bonding and Parent-Child Relationship among Tertiary Students

Tamaki, K. and Takahashi, J (2013) the Relationship between Adult Attachment Style and Social kills in Terms of the Four-Category Model of Attachment Style. International Journal of Humanities and Social Science Vol. 3 No. 19; November 2013.Access from www.ijhssnet.com/journal/index/ 2123. On $24-5-2$ 